\title{
Some Epistemological Groundwork for a Qualitative Analysis of a Communication Community of Practice
}

\author{
Debora Rolfes and Corey Owen \\ Ron and Jane Graham School of Professional Development, College of Engineering \\ University of Saskatchewan \\ debora.rolfes@usask.ca,corey.owen@usask.ca
}

\begin{abstract}
This paper describes a study that attempts to assess learning transfer in an engineering communication programme through a qualitative study using narrative and rhetorical theory, both of which are humanistic theories that have only recently been considered in such assessment. The communication programme attempts to foster a communication community of practice among its students, and thereby ensure that the skills they cultivate in the classroom can be applied in the various contexts provided by the engineering profession. The researchers use narrative and rhetorical theory to analyze transcripts of in-depth interviews, in order to detect evidence of what Etienne Wenger would regard as an identity of participation.
\end{abstract}

Keywords: Professional Communication, Transfer Theory, Professional Identity, Rhetorical Theory, Narrative Theory

\section{INTRODUCTION}

As Jonte Bernhard and Caroline Bailie observe, researchers tend to question the value of qualitative approaches to research in engineering education (EER) because of a lack of standards by which to evaluate such approaches [1][2][6][9]. This lack of standards for assessing qualitative approaches is to some extent a reflection of the situation within qualitative research; as Mirka Koro-Ljungberg and Elliot Douglas observe in a 2008 study, many qualitative studies found in the Engineering Education Research literature lack careful reflection on their methodology, and rely on inconsistent epistemological assumptions [7]. As scholars in humanities, we are used to evaluating knowledge claims based on qualitative research, yet pursuing our research in a college that traditionally requires knowledge claims to be evaluated through quantitative research prompted us to reflect carefully on the epistemological foundations of qualitative research and consider how these foundations determine and constrain our procedural choices. While there is indeed a fair degree of diversity (and disparity) in qualitative studies (and, to be fair, quantitative studies to a certain extent as well), a lack of clear standards is not the only factor in the hesitancy of engineering faculty to recognize the value of qualitative approaches; the professional identity of engineering faculty naturally encourages allegiance to particular types of inquiry: "Quantitative methodologies, large samples, precise parameters, and the elimination of confounding variables are still the hallmarks of rigorous research in most science, technology, engineering, mathematics (STEM) disciplines" [9]. In spite of the tendency to favour quantitative research and maintain reservations about qualitative research, researchers with STEM backgrounds are beginning to see the need for research in engineering education that can explore the "highly complex social interactions" that learning requires [9]. Because of this tendency to distrust qualitative research, whether because of it's perceived epistemological and methodological inconsistencies or the tendency of the audience to discount the evidence it presents, qualitative researchers such as Donald E. Polkinghorne assert that we must examine our epistemological and methodological assumptions in order to persuade an audience of the validity of narrative research (11).

In this paper, we briefly explore the epistemological and methodological assumptions that inform our qualitative study of our professional communication program, which is modeled, in part, on Wenger's concept of community of practice. As Wenger suggests, a community of practice confers identity upon its members, yet how can researchers measure the success or failure of such a community? In our study, we attempt to measure the efficacy of our approach through a narrative analysis of the sort of rigorous interviews recommended by Brent in order to measure learning transfer [4]. Also, we attempt to describe the degree of identification students experience with our community through the use of Kenneth Burke's concept of terministic screens, an approach to analyzing language that elucidates the perspective animating a series of terms. After providing an epistemological and methodological account of our 
qualitative approach, we describe our study and briefly project the categories our study will likely uncover.

\section{RESULTS AND DISCUSSION}

\subsection{Participation and Identity}

At the Ron and Jane Graham School of Professional Development in the College of Engineering at the University of Saskatchewan, we attempt to improve students' communication skills by encouraging them to develop what Etienne Wenger would refer to as an "identity of participation" [13]. According to Wenger's social theory of learning, learning does not happen simply through the transmission of knowledge from teacher to student, or even from the application of learned principles, but from development of an "identity of participation," that is, through the student's recognition that she has joined a community of practitioners, and thus is committed to the process of perpetual learning that such a community implies; as Wenger argues, learning that does not contribute to the formation of a professional identity remains mere information: "When information does not build up into an identity of participation, it remains alien, literal, fragmented, unnegotiable. ...to know in practice is to have a certain identity so that information gains the coherence of a form of participation" [13]. Thus, proper learning transfer requires the formation of such an identity. A typical engineering college is particularly effective at developing a community of practice; in no other professional college do the students identify themselves by their professional designation even before they have completed their programmeme requirements: medical students wouldn't dare call themselves doctors, nor would pharmacy students refer to themselves as pharmacists, nor would law students refer to themselves as lawyers, yet engineering students frequently describe themselves as engineers. Unfortunately, as Sullivan and Kedrowicz argue, since these students generally perceive themselves as particularly skilled at math and science, and less so at writing and presenting, "soft" skills such as communication skills are often excluded from the engineering student's identity [12]. As a result, engineering students often maintain an identity that excludes, or even actively resists, the development of effective communication skills [10].

\subsection{The Problem of Assessment}

While we'd like to believe that our students are developing general rhetorical skills that they can deploy effectively in a variety of situations through the formation of an identity that includes both "rhetoric-practitioner" and "engineer," we are conducting a study to determine whether, and if so, to what degree, our approach is achieving the desired outcome. As Rebecca Nowacek observes, instructors need to conduct research on learning transfer, even though it is notoriously difficult to develop the necessary tools for such research because of the difficulty of assessing students' work in the classroom:

Assessment poses particular challenges to instructors teaching for transfer. The institutional and epistemological structures of disciplines can make it difficult for instructors-as-audience to see and value the connections students make. And yet, if instructors aim to be teaching for transfer as handlers and agents, then they need to see those connections and evaluate them on their merits. Instructors in their capacity as handlers not only need to make space for students to see and sell connections, they need to create spaces where instructors in their capacity as audience can recognize and value connections. [8]

According to Doug Brent, one of the reasons that we find it difficult to develop tools to assess the efficacy of our courses in the classroom is because students are particularly adept at learning the skills needed to pass exams, yet are often unable to apply the new knowledge in a slightly different context; they have difficulty transferring their learned skills from an academic context to a professional one [4]. Activity theorists locate the difficulty of transferring a skill from the classroom to the workplace in the different intentionality that governs their action in each context [4]. As a result, measuring the effect of a given intervention on exam grades would not likely provide an accurate reflection of learning transfer, because the intentionality with which a student writes an exam is fundamentally different from that with which a student applies a skill.

We believe that transfer can be detected-to some degree - through a student's engagement with rhetorical concepts in her reflection on her activities in extracurricular and professional contexts, which reveals her understanding of the general applicability of such rhetorical principles. Such awareness and reflection suggest - and promote - an identity of participation. Thus, in order to gather evidence of learning transfer, Brent suggests, "Rather than directly probing students for explicit instances of transfer, we will need to infer from field observation or rigorous interviews, or both, the academic experiences that students are using as background to their new learning" (4). While field observation would be advantageous for assessing learning transfer, we lack the resources for such an investigation; therefore, we opted to apply narrative and rhetorical theory to rigorous interviews as a means of determining the degree to which students have developed an identity of practice, an identity that would suggest the presence of successful learning transfer. Such an approach naturally relies on qualitative, rather than quantitative, knowledge claims. 


\subsection{Narrative Theory and Rhetorical Theory}

One of the central problems with qualitative research pertains to validity [11]. Narrative research, a qualitative research approach, is potentially questionable not only to researchers in engineering and engineering education, but also to more conservative researchers in the social sciences; in order for such researchers to recognize the validity of qualitative research, narrative researchers such as Polkinghorne argue that a broader spectrum of evidence must be permitted. As a potential solution to the problem of validation across diverse epistemological frameworks, he contends that

different kinds of knowledge claims require different kinds of evidence and argument to convince readers that the claim is valid. Nevertheless, there is general understanding of the concept of validation that is applicable, and perhaps acceptable to narrative researchers and conventional researchers. [11]

Polkinghorne invokes argumentation theory, an interdisciplinary body of knowledge that draws on the disciplines of epistemology, logic, and rhetoric, to elucidate his universal conception of validation. He observes that "validity judgments do not yield simple acceptance or nonacceptance responses" in conventional quantitative or narrative research; rather, in the former, statistical analyses indicate the level of confidence an audience might grant a knowledge claim, and in that latter, "[r]eaders are asked to make judgments on whether or not the evidence and argument convinces them of the level of plausibility, credibleness, or trustworthiness of the claim" [11]. The structure of such arguments is not predetermined; instead, a researcher presents a collection of evidence, such as quotations from a text, and explains why her interpretation is preferable to other possible interpretations of the evidence. The candid discussion of the method is thus a necessary stage of the argument, for it allows the researcher to

defend the appropriateness of the meaning attributed to the words and phrases of the text by providing the context in which they were made, or ... describe ways in which his or her own background experiences produced understandings through interactions with the text. [11]

Thus the knowledge claims of narrative research are validated not by the generic conventions and quantitative evidence of scientific discourse, but rather by the conventions of argumentation, which is informal, situated, subject to ambiguity, and evaluated on a continuum; careful descriptions of epistemological assumptions and methodological approaches are essential for persuading an audience to grant validity to a narrative study.
Narrative research, and rhetorical analysis, are useful tools for investigating identity because such approaches are less interested in the facticity of the information provided by participants, and more interested in the qualities of the participant's identity that are manifested through her language and patterns of thought. As Polkinghorne writes, "Storied evidence is gathered not to determine if events actually happened but about the meaning experienced by people whether or not the events are accurately described" [11]. The negotiation of meaning is, to some degree, a function of identity and, according to Wenger, involves a continuous process of participation and reification, concepts that recall the terms praxis and theoria that have pervaded western philosophy since Plato and Aristotle, terms that provide a conceptual framework for the distinction between applied and pure science. At the risk of oversimplifying Wenger's ideas, participation is "the social experience of living in the world in terms of membership in social communities and active involvement in social enterprises"; that is, it is the act through which we gain experience; reification is the process of giving intellectual form to this experience [13]. An identity of participation, through which we actively negotiate the meaning of a certain activity, requires both our active involvement in an activity, and our process of conceptualizing our experiences in order to reflect on, and perhaps improve, our performance. While our method does not enable us to directly observe participants' behaviour in the workplace in order to learn whether they actually form a rhetorical community of practice, we can assume that they are continuously engaged in applying their communication skills, and our interviews are designed to determine whether they have internalized reifications of rhetorical concepts, and whether they are engaged in a process of reflecting on the relationship between these reifications and their own experience.

Polkinghorne identifies four validity threats, all of which are rooted in the fact that "languaged descriptions given by participants of their experienced meaning is not a mirrored reflection of this meaning," and suggests potential methods for improving the validity of a narrative study in the face of these threats. The first threat originates in the inability of language to accurately render the complexity of experienced meaning, and can be addressed through the interviewer encouraging the participant to use metaphorical language, since such language provides the possibility of a greater richness of expression [11]. We address this potential weakness through a terministic analysis of the responses, which allow us to detect the implied beliefs and values, or orientation, of the participant, in relation to the content of the response. Second, a participant may not have access to her awareness of the significance of her reflections at the time of the interview, due to fluctuations in the depth of a person's self-awareness at any given moment. Therefore the interviewer must grant the participant the time to 
reflect on her experience, and must encourage the participant to stay with her reflection in order to enable her to recall more detail [11]; by issuing a survey before and after our participants went on their internship, we prompted them to begin reflecting on their communication experience well in advance of their interview. Third, participants can be hesitant to share details of their experiences with a stranger, especially if those details potentially cast them in a negative light; thus, multiple interviews over a broad time period can help the interviewer build rapport with the participant, and enable the participant to reflect more deeply on their experiences [11]. Multiple interviews were not possible in our study, so we chose an interviewer who, as a recent graduate of the College of Engineering, was a peer of the participants, but who had specialized training in qualitative research. Finally, transcripts of interviews are "creations of an interaction between interviewers and participants"; thus, participants will look for feedback concerning the appropriateness of their responses, and researchers can unconsciously offer such feedback and thereby encourage participants simply to confirm the researchers' expectations of the study. As a result, researchers must "[assume] an open listening stance and carefully [attend] to the unexpected and unusual participant responses" in order to ensure that they are not predetermining the outcome of the interview [11]. Our interviewer was an engineer, not an instructor of professional communication. As Nowacek observes, students can be sensitive to the implied generic expectations of a communication situation [8], so an interview about communication experiences in the College of Engineering could lead the participant to understand that we are exploring the efficacy of our programme, and the participant might intentionally, or unconsciously, formulate responses that conform to our expectations. Again, terministic analysis can help us, to a certain degree, determine whether a response is designed simply to conform to our expectations.

Our study looks for evidence of a community of rhetorical practitioners on two levels. First, on the structural level, we look for evidence of narrativized patterns of constructing and responding to rhetorical situations. The process of narrativization, as Hayden White defines it, is an attempt to reify experience through the structural elements of the genre of narrative, and implies the sort of internalization that contributes to the formation of identity [14]. Second, we use Kenneth Burke's theory of terministic screens to investigate the terminology used by the participants. According to Burke, terministic screens are a component of a dramatistic approach to understanding the nature of language. Like Polkinghorne's approach, Burke's approach does not regard language as simply representative of experience, but as a filter for experience that implies the beliefs and values of the speaker, as a mode of rationalizing their behaviour in the context of a specific situation, and as an attempt to respond to and produce change in the world through symbolic action [5]. As a result, Burke states, "even if a given terminology is a reflection of reality, by its very nature it must be a selection of reality; and to this extent it must function also as a deflection of reality" [5]. The terminology used within a discourse reflects a mode of interpreting a situation, and suggests the parameters within which action can take place [3]. Thus, while narrative analysis focuses on the larger structural features that distinguish narrative from other types of discourse, such as definition or exposition, and the meaning that is conveyed through such features, the concept of terministic screens encourages the researcher to consider the nature of the terminology used within a discourse, and the perspective, attitude, and identity such a terminology implies.

\subsection{Method}

Our study comprises two parts. The first is a survey that gathers general information about participants' perceptions of their level of preparation for the communication challenges presented by practice of engineering in industry. The second part involves in-depth interviews with students about their communication experiences in professional settings.

\subsection{Participants}

The Engineering Professional Internship Program (EPIP) at the University of Saskatchewan is an optional programme that allows engineering students to gain work experience in industry while remaining registered as a student. Placements are for 8,12 , or 18 months. Industry partners post the positions that they have available, and students who are registered in EPIP apply for the positions in which they are interested. Interns are hired into positions through a standard hiring process, involving submitting cover letters and resumes, participating in interviews, and accepting (or rejecting) job offers. ${ }^{1}$

Students are eligible for placement after completing 84 credit units toward their engineering degree (generally, after their third year). Most participants in EPIP will have completed RCM 300 Effective Professional Communication, the required communication course for all disciplines in the College of Engineering. Some will have taken one or more senior communication courses through the Ron and Jane Graham School of Professional Development (SoPD), either as humanities electives in their programme or as part of the Professional Communication Option (PCO).

\footnotetext{
${ }^{1}$ In the spring 2015 placement, about 400 students were eligible to apply to the programme; 175 applied, and 90 students were placed in internships.
} 


\subsection{Procedure}

A Pre-Internship Communication Survey is provided to participants as part of the orientation session before they begin their internship. In May 2015 and January 2015, the survey was done on paper in the orientation meeting. In September 2015, the survey was moved to FluidSurveys, and participants were emailed the link to the survey. In all cases, participation in the survey was entirely voluntary and was administered by the Engineering Students Centre. In these three survey periods, 61 students were eligible to take the survey and 37 students completed it. In September 2015, 65 participants returning from internship were provided a link to a Post-Internship Communication Survey on FluidSurveys; 37 completed the survey. These Pre - and Post-Internship Communication Surveys will continue to be given to internship students for several more years, in order to track whether changes to how communication is taught in the college is affecting students' perceived preparation for professional practice.

The Pre- and Post-Internship Communication Surveys are identical except that the Pre-Internship Survey measures students' expectations of communication requirements in industry and their assessment of their communication strengths and weaknesses before their work experience; the Post-Internship survey asks about students' actual experience of the communication skills required of them during their work placement and measures their assessment of their strengths and weaknesses in light of that experience. The responses before and after internship can be assessed for all participating students, for students who have only the required communication course, and for students who have varying numbers of senior communication courses.

The Post-Internship Communication Survey asked students whether they would be willing to participate in a follow-up, face-to-face interview; from the list of volunteers, four students were chosen to interview, two who had taken only RCM 300, the required communication course, and two who were enrolled in the Professional Communication Option and had taken several senior communication courses. The interviews invited students to reflect on communication challenges they faced while on internship and the strategies they used to manage them.

The interviews were designed to elicit information about the participation of the participants in an identity of practice in two areas: first, did the student describe her engagement with professional communication challenges in ways that reflect a (perhaps, tacit) rhetorical approach to communication; second, did the student use rhetorical language, suggesting a conscious participation in the community of rhetorical practitioners. The interviews were conducted by a graduate student who had completed the Professional Communication Option. The interviewer did not use language taken from rhetorical theory when asking participants to reflect on communication challenges they faced on internship. However, if the participant used rhetorical theory to describe her experience, then the interviewer was able to engage with the participant in the language particular to rhetoricpractitioners. The interviews were transcribed and will be analyzed to look for markers of identity. If the participants have not used rhetorical theory to describe their experiences, then we will have to determine whether the descriptions of dealing with communication challenges suggest a rhetorical orientation. The terminology participants use will tell us whether they engage in such an orientation, even if they do not use the rhetorical terminology we teach in our programme- they will select terms that suggest their consciousness of the concepts of rhetorical exigence, rhetorical audience, constraints, kairos, ethos, pathos, and logos, for instance, without identifying these terms. Such an approach will also help us determine whether a participant is using the terminology without actually approaching communication situations with a rhetorical orientation. The application of narrative theory will provide us of evidence of the degree to which participants have processed and internalized their experiences. While a high degree of narrativization may simply betray a participant's facility at drawing a story out of their raw experience, it will also reveal whether, and if so, perhaps to what degree, the participant has internalized a rhetorical orientation.

\subsection{Anticipated Results}

While we cannot anticipate the outcome of our study, we suspect each of our participants will fall into one of four categories:

1. The participant uses rhetorical terminology and has a rhetorical orientation

2. The participant has a rhetorical orientation but does not use rhetorical terminology

3. The participant uses rhetorical terminology without evidence of engaging in a rhetorical orientation

4. The participant neither uses rhetorical terminology nor provides evidence of engaging in a rhetorical orientation.

Participants who belong to category 1 will most likely have developed an identity of participation, which was likely informed, by some degree, by the communication community of practice we attempt to foster. Participants belonging to category 2 or 3 have some of the elements of an identity of participation, but they have not internalized a rhetorical orientation, or they have either never properly learned, or perhaps consciously or unconsciously abandoned, the terminology we use in our programme. Finally, those who belong to category 4 show no evidence of an identity of participation. 


\section{CONCLUSIONS}

While we have not yet completed our analysis of the in-depth interviews, we hope that the theoretical tools of narrative analysis and terministic screens can help us determine whether engineering students at the University of Saskatchewan who go on internship have developed a certain degree of an identity of participation, and whether they are able to transfer the skills and knowledge they attain in our communication programme to the various rhetorical exigences they face when they enter the workplace. While we have not developed a clear plan of how we might modify our programme if we find little evidence of identity formation and learning transfer, such feedback will at least help us determine what sort of communication problems our students face when they enter a professional environment, and thereby help us adapt our programme to better suit their needs.

\section{Acknowledgements}

We would like to thank Liz Kuley and Chris Martin for their assistance with the surveys and interviews, as well as our colleagues at the Graham School for their support and suggestions.

\section{References}

[1] Caroline Baillie and Elliot P. Douglas, "Confusions and Conventions: Qualitative Research in Engineering Education, Journal of Engineering Education, vol. 103, no. 1, pp. 1-7, 2014.

[2] Jonte Bernhard and Caroline Baillie, "Standards for Quality of Research in Engineering Education," in Proc. REES Research in Engineering Education Symposium, (Kuala Lumpur, Malaysia; 4-6 July 2013), 8 pp., 2013.

[3] David Blakesley, The Elements of Dramatism, New York: Longman, 2002, 212 pp. \{ISBN: 0-205-33712-0\}

[4] Doug Brent, "Transfer transformation, and rhetorical knowledge: insights from transfer theory," Journal of Business and Technical Communication, vol. 25, no. 4, pp. 396-420, 2011.

[5] Kenneth Burke, "Language as Action: Terministic Screens," On Symbols and Society, ed. Joseph R. Gusfield, Chicago: U of Chicago P, 1989, pp. 114-125. \{ISBN: 0-226-08078-1\}

[6] Jennifer M. Case and Gregory Light, "Emerging Methodologies in Engineering Education Research," Journal of Engineering Education, vol. 100, no. 1, pp. 186-210, 2011.

[7] Mirka Koro-Ljungberg and Elliot P. Douglas, "State of qualitative research in engineering education: meta-analysis of
JEE articles, 2005-2006," Journal of Engineering Education, vol. 97 , no. 2, pp. 163-175, 2008.

[8] Rebecca Novacek, Agents of Integration: Understanding Transfer as a Rhetorical Act, Carbondale: Southern Illinois UP, 2011, 167 pp. \{ISBN: 978-0-809-33048-5\}

[9] Carolyn Oliver, Susan Nesbit, and Niamh Kelly, "Dissolving Dualisms: How Two Positivists Engaged With Non-Positivist Qualitative Methodology," International Journal of Qualitative Methods, vol. 12, pp. 180-94, 2013.

[10] Corey Owen and Debora Rolfes, "Communication Class Size and Professional Identity," in Proc. ASEE American Society for Engineering Education Conf., (Seattle, WA; 14-17 June 2015), 11 pp., 2015.

[11] Donald E. Polkinghorne, "Validity Issues in Narrative Research," Qualitative Inquiry, vol. 13, no. 4, pp. 471-486, 2007.

[12] Katie R. Sullivan and April A. Kedrowicz, "Gendered Tensions: Engineering Student's [sic] Resistance to Communication Instruction," Equality, Diversity, and Inclusion: An International Journal, vol. 31, no. 7, pp. 596-611, 2012.

[13] Etienne Wenger, Communities of Practice: Learning, Meaning, and Identity, Cambridge: Cambridge UP, 1998, 318 pp. $\{$ ISBN: 978-0-521-66363-2\}

[14] Hayden White, "The Value of Narrativity in the Representation of Reality," On Narrative, ed. W. J. T. Mitchell, Chicago: U of Chicago P, 1981, pp. 1-24. \{ISBN: 0-226-53217$8\}$ 